УДК $81 ’ 23$

\title{
T.Е. Машанло
}

\section{ВЛИЯНИЕ УРОВНЯ ВЛАДЕНИЯ ИЗУЧАЕМЫМ ЯЗЫКОМ НА ПОКАЗАТЕЛИ ПРОЦЕССА ЧТЕНИЯ ИНОСТРАННЫХ ТЕКСТОВ РУССКО-КИТАЙСКИМИ И КИТАЙСКО-РУССКИМИ БИЛИНГВАМИ}

\author{
Работа выполнена в рамках государственного задания Министерства образования \\ и науки Российской Федерации, номер индивидуального плана работ 1.8901.2017/9.10.
}

\begin{abstract}
Представлены результаты исследования с использованием метода регистрации движений глаз, направленного на выявление влияния уровня владения L2 на показатели процесса чтения у русско-китайских и китайско-русских учебных билингвов. У русских студентов при чтении на китайском продолжительность фиксаций и частота регрессий продемонстрировали тенденцию на понижение с повышением уровня владения L2, длина саккад осталась неизменной у респондентов всех уровней. У китайских респондентов не было обнаружено зависимости значений показателей чтения от уровня владения L2. Это может быть связано со значительным опытом использования алфавитных систем письменности китайскими респондентами.

Ключевые слова: движения глаз; билингвизм; китайский язык; русский язык; чтение.
\end{abstract}

Введение. Исследования процесса чтения уже долгое время представляют интерес для лингвистов и психологов. Огромную роль в изучении данного процесса играют окулографические методы, т.е. методы регистрации движений глаз. Первые исследования процесса чтения с применением данных методов имели место почти полтора столетия назад, однако на настоящий момент большая их часть была посвящена процессу чтения на языках, использующих алфавитные системы письменности. Языкам, использующим другие системы, уделяется значительно меньше внимания.

Основополагающим различием между системами письменности является способ кодирования единиц языка на письме. Так, алфавитные системы устанавливают соотношение между графемой на письме и фонемой в языке, слоговые системы - между графемой и слогом, логографические - между графемой и морфемой (которая может совпадать с целым словом). Наименьшей единицей в алфавитных системах письменности в таком случае является буква или сочетание букв, в логографических - иероглиф.

Алфавитные системы конкретных языков могут различаться по способу реализации системы письменности в конкретном языке, т.е. орфографии. Так, например, и русский, и английский являются алфавитными системами, но различаются на уровне орфографий. Орфографии могут различаться по степени прозрачности, т.е. регулярности соотношения между графемами и фонемами: высокой степенью прозрачности отличается, например, финская орфография. Подобные орфографии также называются неглубокими и характеризуются строгим соответствием между звуками и буквами, которыми они кодируются. При чтении таких орфографий читатель не испытывает никаких проблем в извлечении звуковой составляющей слова из его написания. Русская орфография также отличается относительно высокой степенью прозрачности. Регулярность русской орфографии обусловливается соблюдением слогового принципа русской графики - признак мягкости / твёрдости у согласного отражается при помощи последующей гласной буквы, что в свою очередь приводит к сокращению необходимого количества символов в алфави- те [1]. Примером глубокой орфографии может послужить английская орфография, в которой с одним сочетанием букв на письме могут соотноситься несколько произношений. Наиболее известен, наверное, пример сочетания букв «ough», имеющий до десяти различных произношений. Регулярность соответствий, без сомнения, влияет на характер чтения текстов в различных орфографиях. В орфографиях с относительно регулярным соотношением графем и фонем читатель может прибегать к стратегии «озвучивания» слова, в то время как в глубоких орфографиях читатель чаще обращается к слову напрямую в обход графемно-фонемного декодирования [2. С. 19].

Китайская письменность, являясь логографической, устанавливает соответствие между графемами и морфемами (которые почти всегда также являются слогами и реже - целыми словами). У каждого иероглифа имеется собственное произношение, некоторые иероглифы также могут соотноситься с несколькими прочтениями. Китайский язык характеризуется высоким уровнем омонимии, даже с учётом тонов это приводит к тому, что у один и тот же слог может иметь несколько способов записи в зависимости от значения, например, слог xiàng соотносится со следующими иероглифами: 项“затылок', 象 ‘слон”, 向 ‘к’, 像 ‘быть похожим’ и др.

Требует уточнения расхожее мнение, что китайские иероглифы напрямую кодируют значение в обход фонетического уровня. Действительно, если изначально китайская письменность являлась письменностью пиктографической, т.е. напрямую соотносящей изображение объекта с объектом, то на сегодняшний день не более двух процентов китайских иероглифов представляют собой пиктограммы. За многотысячелетнюю историю внешний вид иероглифов претерпел значительные изменения. Около $80 \%$ современных китайских иероглифов представляют собой фоноидеограммы, содержащие в своём составе как минимум два элемента - фонетический и семантический радикал. Фонетический радикал представляет собой структурный элемент иероглифа, указывающий на его произношение, семантический радикал указывает на то, к какой категории относится иероглиф. Тем не 
менее фонетический радикал не может являться надёжным указателем на произношение конкретного иероглифа; зачастую производный иероглиф отличается от него тоном, совпадает только рифмой, а иногда и вовсе имеет другое произношение. Семантический радикал также не может служить надёжным индикатором значения всего иероглифа. В самых надёжных случаях он может указывать на принадлежность иероглифа к какой-либо категории [3]. Например, все иероглифы, содержащие семантический радикал 乌 乌iăo, 'птица', служат для обозначения какой-либо птицы (鸡 $j \bar{\imath}$ - 'петух', 甲鸟 $y \bar{a}$ - 'утка', 鹃 juān - 'кукушка' и т.д). В других случаях иероглиф может иметь значение, никак не связанное со значением семантического радикала, например ключ 耳 $е r r$, 'ухо' встречается как в иероглифах, имеющих связь с данным значением, например 闻wén, 'нюхать', так и в иероглифах, в которых такая связь не прослеживается - 耳只zhi', 'профессия'.

Наконец, необходимо отметить две характерные особенности китайской системы письменности, связанные с её визуальными характеристиками. Вопервых, все иероглифы на письме имеют одинаковую ширину и фиксированную максимальную высоту, равную ширине. Так, иероглиф - $y \bar{\imath}$, 'один', состоящий из одной черты, занимает в тексте столько же места, сколько и иероглиф 藏 cáng, 'прятаться', содержащий 17 черт. Таким образом, китайский текст представляет собой сочетание иероглифов различной визуальной сложности. Во-вторых, в китайском тексте границы слов не обозначены пробелами. Незначительные пробелы присутствуют между иероглифами, т.е. на границах морфем, но не слов.

В процессе чтения у читателя создаётся впечатление, что его глаза находятся в постоянном движении. Тем не менее большую часть времени глаза находятся в относительно неподвижном состоянии - эти промежутки времени называются фиксациями. Именно во время фиксаций читатель извлекает наибольшую часть информации из текста. Переход между фиксациями осуществляется быстрыми, скачкообразными движениями, называемыми саккадами. Извлечение информации во время саккад не представляется возможным, в силу того что изображение, попадающее на сетчатку глаз, оказывается слишком размытым [4. С. 373].

Для алфавитных систем письменности средняя продолжительность фиксаций находится в пределах от 200 до 250 мс в зависимости от содержания текста. Средняя длина прогрессивных саккад при чтении составляет 8-9 знаков и является постоянной независимо от размера шрифта; предпочтительное конечное положение саккады при первой фиксации на слове приходится, как правило, на промежуток между началом и серединой слова. Частота регрессивных саккад составляет от 10 до 25\% от общего количества саккад. Не все слова при чтении фиксируются в фовеальном зрении: значимые слова фиксируются в $85 \%$ случаев, а вспомогательные - в 35\%. Наконец, диапазон восприятия участок текста, из которого читатель извлекает информацию в процессе чтения, - составляет примерно 20 знаков - 3-4 знака слева от точки фиксации, 14-15 знаков справа от точки фиксации [4. С. 375-380].
Первые исследования процесса чтения иероглифической письменности датируются 20-ми гг. XX в. В тот период преимущественным направлением письма для китайского языка еще было письмо сверху вниз. Исследование, проведённое Майлзом и Шенем, показало, что носители языка показывали лучшие показатели при вертикальном чтении, чем при горизонтальном [5]. В скором времени интерес к исследованию процесса чтения китайской письменности угас. Лишь через 50 лет научное сообщество снова обратило свои взоры на эту систему письменности. Возрождение интереса к китайской письменности обусловлено тем, что она в своём основании имеет ряд существенных отличий от алфавитных систем письменности. Тем не менее, сравнивая процессы чтения в двух системах письменности, можно отметить некоторые существенные сходства. Так, в рамках исследования Ф. Суня установлено, что средний темп чтения на китайском языке составил 580 иероглифов в минуту, что в пересчёте на слова даёт темп, сопоставимый с темпом при чтении на английском языке (386 и 382 слова в минуту соответственно) [6. С. 193]. Средняя продолжительность фиксаций также не находит существенных различий в двух системах письменности: в среднем читатель тратит 230-265 мс на одно китайское слово [6. С. 200; 7. С. 214].

По-видимому, не отличается и частота регрессий: при чтении предложений на понимание, частота регрессий составляет около 15\%. Тем не менее между сравниваемыми системами существуют и различия, обусловленные большей информационной плотностью китайского текста, в котором один знак на письме соотносится с целой морфемой. Так, диапазон восприятия носителей китайского языка оказывается у́же двадцатизнакового диапазона носителей английского языка. В среднем носитель китайского языка воспринимает один иероглиф слева от точки фиксации и до 3-4 иероглифов справа от точки фиксации. Короче оказывается и средняя длина саккад: в среднем при чтении на китайском носитель передвигается вперёд по тексту на 2-3,2 знака [6. С. 193; 7. С. 213; 8. С. 7].

Стоит также отметить тот факт, что читатель китайского текста гораздо более чувствителен к изменениям в размере шрифта. Значительное увеличение шрифта приводит к сокращению длины саккад [9. C. 489]. Также имеются противоречивые данные относительно предпочтительного конечной позиции саккады. Различные исследования свидетельствуют о трёх возможных стратегиях выбора конечной позиции саккад. Согласно первой точке зрения, читатели направляют свой взгляд случайным образом, фиксируясь как на иероглифах, так и на промежутках между ними [7. С. 213]. Согласно другой точке зрения, у читателей просматривается тенденция к выбору центра слова в качестве предпочтительной конечной позиции саккады [10]. Наконец, третья точка зрения сводится к тому, что читатели используют информацию о свойствах зафиксированного в настоящий момент слова для принятия решения о том, куда направить следующую саккаду [11. С. 1154].

Представляет интерес трёхъязычное исследование С. Ливерседжа и др. [8]. Авторы исследовали чтение англо-, финно- и китаеязычных монолингвов, которые 
читали 8 коротких текстов, составленных при помощи множественного обратного перевода. Таким образом авторы получили возможность контролировать содержание текста и сконцентрироваться на межъязыковых различиях в процессе чтения. Было установлено, что финские респонденты делали больше фиксаций на слове, чем читатели китайских текстов. По-видимому, это вызвано большей средней длиной финского слова. В то же время средняя продолжительность фиксаций для финского языка оказалась ниже, чем для китайского. Длина саккад также оказалась зависимой от средней длины слова в языке: самые короткие саккады наблюдались в китайском языке, самые длинные - в финском. Во всех трёх приведённых характеристиках английские респонденты показывали значения, находящиеся между двумя группами. Несмотря на различия в характеристиках, участники показали одинаковый уровень понимания текстов на всех трех языках, общая продолжительность чтения текстов также оказалась независимой от языка текстов. Всё это может свидетельствовать о том, что читатели различных систем письменности прикладывают одинаковые усилия для когнитивной обработки языкового материала, - эти усилия, однако, оказываются по-разному перераспределены в пределах предложения в разных языках.

Все приведенные выше показатели касаются ситуации монолингвального чтения. Исследования процесса чтения у билингвов относительно молоды и также в основном сконцентрированы на изучении языков, использующих алфавитные системы письменности. В ситуации такого билингвизма читатель может опираться на опыт, приобретённый им во время усвоения родного языка, ему нужно только приспособиться к отличной от его родного языка орфографии. Так, исследование на примере голландскоанглийских билингвов показало, что билингвы с высоким уровнем владения английским языком делают больше фиксаций $(20 \%)$, прибегают к более коротким саккадам (12\%), а также реже пропускают слова (4,6\%) при чтении на втором языке [12].

Но что происходит, когда читатель сталкивается не просто с иной орфографией, но с иной системой письменности? В 1986 г. Эверсон провел исследование, в котором показатели чтения китайского текста англоязычными начинающими и продолжающими студентами сравнивались с аналогичными показателями чтения тех же текстов носителями языка [13]. М. Эверсон обнаружил значительные отличия в показателях чтения у начинающих и продвинутых студентов. Начинающие студенты чаще и дольше фиксировались на словах, а также имели больший процент регрессивных саккад, чем носители языка. Продолжающие студенты продемонстрировали прогресс по всем показателям кроме средней продолжительности фиксаций. Автор объясняет это явление тем, что начинающим читателям необходимо сделать большее количество фиксаций на иероглифе, для того, чтобы его распознать, однако вполне вероятно, что читатели-билингвы достаточно рано достигают минимально возможного значения продолжительности фиксации, что в свою очередь мешает им достигнуть того уровня автоматизма, который свойственен носителям китайского языка.
Исследования процесса чтения в двух системах письменности по-прежнему остаются сравнительно редкими. В связи с этим в рамках данного исследования была поставлена задача выявить основные показатели чтения у учебных билингвов, сталкивающихся с системой письменности, построенной на иных принципах кодирования фонологической информации, и определить, каким образом показатели чтения зависят от уровня владения вторым языком.

Основная гипотеза данного исследования заключается в следующем: испытуемые, набравшие более высокий балл в тесте на определение уровня навыка чтения, покажут лучшие показатели чтения, т.е. показатели, приближающиеся к показателям носителей языка. Подобный результат будет свидетельствовать о том, что с течением времени искусственные билингвы способны адаптироваться к чтению текстов, записанных при помощи другой системы письменности. Данная гипотеза проверялась экспериментально с применением окулографического оборудования.

Участники. В эксперименте приняли участие 59 респондентов: 31 русско-китайских билингв в возрасте от 18 до 26 лет и 28 китайско-русских билингвов в возрасте от 20 до 27 лет. Родным языком всех респондентов был либо русский, либо китайский. Все респонденты также сообщили о знании английского языка. Все участники имели нормальное или скорректированное до нормального зрения. Они не знали о цели эксперимента и приняли в нём участие добровольно и безвозмездно.

Материал. Материалом для эксперимента послужили 50 текстов «Теста по русскому языку как иностранному» (ТРКИ) [14-16] и «Теста на определение уровня китайского языка» (HSK, Hànyǔ Shuǐpíng Kăoshì) [17, 18]. Тексты на каждом языке (по 25 текстов) были разбиты на две группы: 13 простых текстов (ТРКИ-І, HSK4), соответствующих уровню В1 по Европейской системе уровней владения иностранным языком (Common European Framework of Reference for Languages) [19], в том числе по одному пробному тексту, не учитываемому в анализе, и 12 сложных текстов (ТРКИ-II, НSK5), соответствующих уровню В2. Тексты также были сбалансированы по количеству слов: в среднем русские тексты низкого уровня сложности содержали 83 слова $(\mathrm{SD}=10,62)$, аналогичные китайские тексты - 133,58 иероглифов (SD = 11,97), тексты высокого уровня сложности содержали 98,58 слова $(\mathrm{SD}=9,53)$ и 167,33 иероглифов $(\mathrm{SD}=20,71)$ соответственно.

Материалом для тестов на определение уровня владения языком послужили учебные тексты ТРКИ [14-16, 20-22] и HSK [17, 18, 23, 24] уровней A2-C1. Каждый тест состоял из текстов четырёх уровней сложности и 26 вопросов.

Для оценки языкового опыта билингвов использовалась Анкета опыта и знания языков (LEAP-Q) на русском и китайском языках для русскоязычных и китаеязычных билингвов соответственно [25].

Оборудование. Эксперимент был создан при помощи программного обеспечения SMI Experiment Center 3.7. Для показа стимулов использовался 22дюймовый ЖК-монитор Dell с частотой обновления картинки 60 Гц и разрешением 1680×1050 пикселей. 
Русские стимулы были набраны моноширинным шрифтом Courier New (24 кегля), размер одной буквы составлял 26 пикселей в ширину, или $0,65^{\circ}$ визуального угла. Китайские стимулы были набраны шрифтом SimSun (20 кегель), размер одного иероглифа составил 35 пикселей в ширину, или $0,87^{\circ}$ визуального угла. Все стимулы представляли собой текст, набранный черным цветом на белом фоне. Расстояние между строчками составило 137 пикселей. Во время эксперимента испытуемые сидели на расстоянии 65 см от дисплея. В течение всего эксперимента расстояние до дисплея было фиксированным благодаря использованию стойки для фиксации головы. Запись движений глаз осуществлялась при помощи прибора для слежения за движениями глаз SMI Red 500 и программного обеспечения SMI iViewX 2.7, запись осуществлялась в бинокулярном режиме с частотой записи 500 Гц.

Процедура. Исследование проходило в два этапа. Этапы проходили в разные дни и промежуток между ними не составлял больше месяца. На первом этапе испытуемым предлагалось пройти тестирование, позволяющее оценить уровень владения иностранным языком, а также заполнить Анкеты опыта и знания языков. Данный этап испытуемые проходили в группах от 3 до 10 человек. Продолжительность данного этапа составила от 30 до 60 минут.

Во время второго этапа испытуемые по одному проходили эксперимент в тихой хорошо освещенной комнате. Перед заходом в комнату испытуемые получали инструкцию о том, что им необходимо будет внимательно прочитать тексты на двух языках, также сообщалось, что после каждого текста на экране будут появляться вопросы, направленные на оценивание понимания. После этого начиналась подготовка к эксперименту. Участники усаживались по центру монитора на расстоянии 65 см от дисплея.

Перед началом эксперимента испытуемым предлагалось ознакомиться с инструкцией к эксперименту. Все инструкции были написаны на русском языке, однако если у участника возникали вопросы по поводу процедуры эксперимента, он мог получить необходимые уточнения на китайском языке. С целью осуществления контрбалансировки одна половина респондентов начинала эксперимент с чтения китайских текстов, другая - с чтения русских текстов. Каждый языковой блок был разбит на 9 подблоков: 1 тестовый подблок с 1 текстом низкого уровня сложности и 8 экспериментальных подблоков с текстами разных уровней сложности. Порядок появления стимулов был рандомизирован таким образом, чтобы не допустить возможность появления четырёх текстов одного уровня сложности подряд. Девятиточечная процедура калибровки проходила перед началом каждого подблока, после чего проходила процедура валидации калибровки, в которой принимались значения с ошибкой, не превышающей $1^{\circ}$ визуального угла. После успешной процедуры калибровки на экране появлялся фиксационный крест и текст, сообщающий респонденту, что для появления стимула ему необходимо зафиксировать взгляд на кресте. Фиксационный крест был расположен таким образом, чтобы первый символ последующего стимула находился на 5 пиксе- лей правее центра фиксационного креста. На фиксационном кресте была расположена триггерная зона, срабатывавшая после 700 мс непрерывной фиксации. По окончании чтения текста испытуемый отвечал на два вопроса по содержанию текста. Каждый вопрос представлял собой утверждение о том, о чём в тексте говорилось напрямую, и подразумевал ответ «да» или «нет». Вопросы были составлены таким образом, что одна половина ответов была утвердительной, другая отрицательной. После ответа на вопросы перед испытуемым снова появлялся экран с фиксационным крестом. После каждых трёх текстов у испытуемых была возможность взять перерыв. Между двумя блоками испытуемым также предлагалось отдохнуть в течение пяти минут. Все тексты на китайском языке умещались на одной странице. Русские тексты умещались на двухчетырёх страницах, переход к предыдущим страницам был невозможен. Общая продолжительность второго этапа составила от 40 минут до 1 часа 30 минут.

Анализ данных. Для предварительной обработки и анализа данных использовалось программное обеспечение SMI BeGaze 3.7 и интегрированная среда разработки RStudio [26] для языка R [27], в том числе пакеты tidyverse [28], lme4 [29]. Сырые данные импортировались в программное обеспечение SMI BeGaze 3.7, после чего осуществлялась их обработка при помощи встроенного алгоритма обнаружения событий в режиме «High Speed Event Detection» с минимальной продолжительностью фиксаций 100 мс. После этого все стимулы подверглись визуальному осмотру - из анализа исключались стимулы, содержащие серьезные огрехи: смещённые фиксации, отсутствующие саккады, саккады, выходящие за пределы экрана. Далее данные импортировались в программную среду RStudio языка $\mathrm{R}$ для дальнейшей обработки. Для анализа использовались только данные с коэффициентом отслеживания (tracking ratio), превышающим 80\%. Из анализа также были исключены тексты, в ответах на которые читатели допустили ошибки. Таким образом, для анализа показателей чтения на китайском языке остались доступны данные 518 текстов (277 текстов, прочитанных носителями языка, 241 - русскими билингвами), для анализа показателей чтения на русском языке - 692 (460 носителями языка, 232 - китайскими билингвами). Из анализа были исключены саккады с вертикальным отклонением, превышающим 68,5 пикселей (т.е. половину межстрочного интервала) и все значения, отличающиеся от среднего на три стандартных отклонения. После этого данные каждого наблюдения были усреднены. Для анализа данных чтения на иностранном языке использовался метод смешанных линейных моделей, реализованный в языке $\mathrm{R}$ при помощи пакета lme4. В качестве случайных эффектов в моделях использовались идентификаторы текстов и респондентов.

Результаты. Предварительные описание данных без учёта уровня владения вторым языком представлено в статье [30]. Данные по основным показателям чтения для русских студентов представлены по курсам. Это связано с тем, что уровень владения вторым языком, определявшийся тестом, плохо коррелировал с языковым опытом студентов; однако не вызывает сомнения тот факт, что студенты пятого курса владе- 
ют вторым языком лучше, чем студенты второго курса, поэтому представляется необходимым рассмотреть данные для студентов различных курсов по отдельности. Более дробное представление группы китайских респондентов, однако не представляется возможным в связи с тем, что все носители китайского языка изучали русский язык до приезда в Россию в существенно различающихся условиях.
Результаты чтения простых текстов на китайском языке представлены в табл. 1. В этой и последующих таблицах принят ряд условных сокращений: КУ - количество участников, КТ - количество текстов, КБТ количество баллов за текст, ПФ - средняя продолжительность фиксаций, ДПС - средняя длина прогрессивных саккад, ДРС - средняя длина регрессивных саккад, ЧР - частота регрессий.

Показатели чтения простых китайских текстов

\begin{tabular}{|c|c|c|c|c|c|c|c|}
\hline & КУ & КТ & КБТ & ПФ (мс) & ДПС (знаков) & ДРС (знаков) & ЧР \\
\hline Носители & 22 & 132 & - & $195,68(20,91)$ & $3,21(1,17)$ & $3,13(2,35)$ & 24 \\
\hline 1-й курс & 5 & 13 & $11-15$ & $476,57(105,35)$ & $1,05(0,38)$ & $2,51(1,37)$ & 32 \\
\hline 2-й курс & 5 & 22 & $43-60$ & $334,07(64,68)$ & $1,18(0,46)$ & $2,47(1,32)$ & 29 \\
\hline 3-й курс & 4 & 24 & $42-57$ & $398,37(99,23)$ & $1,14(0,53)$ & $2,75(2,03)$ & 27 \\
\hline 4-й курс & 9 & 55 & $41-62$ & $330,63(63,57)$ & $1,12(0,4)$ & $2,37(1,42)$ & 25 \\
\hline 5-й курс & 6 & 29 & $42-56$ & $365,09(84,96)$ & $1,08(0,57)$ & $3,31(1,99)$ & 24 \\
\hline
\end{tabular}

Самое значительное снижение продолжительности фиксаций зафиксировано при переходе с 1-го (476 мс) на 2-й курс (334 мс). В целом у студентов 25-х курсов наблюдаются схожие показатели продолжительности фиксаций (331-398 мс), сильно уступающие показателям носителей языка (196 мс). У носителей китайского языка средняя длина регрессивных саккад $(3,13$ знаков) оказалась несколько короче длины прогрессивных саккад (3,21 знака), напротив, у русских респондентов средняя длина регрессивных саккад (от 2,37 до 3,31 знака) оказалась существенно больше длины прогрессивных саккад (1,05-1,18 знака). У русскоязычных студентов наблюдается тенденция к снижению частоты регрессий с увеличением языкового опыта - с $32 \%$ для студентов 1-го курса до 24 \% для студентов 5-го курса, достигших таким образом показателей носителей языка.

Результаты чтения сложных текстов на китайском языке представлены в табл. 2.

Показатели чтения сложных китайских текстов

\begin{tabular}{|c|c|c|c|c|c|c|c|}
\hline & КУ & КТ & КБТ & ПФ (мс) & ДПС (знаков) & ДРС (знаков) & чР \\
\hline Носители & 22 & 145 & - & $193,22(19,54)$ & $3,22(1,18)$ & $3,17(2,45)$ & 24 \\
\hline 1 -й курс & 5 & 4 & $11-15$ & - & - & - & - \\
\hline 2-й курс & 5 & 14 & $43-60$ & $355,12(57,61)$ & $1,08(0,31)$ & $2,20(0,74)$ & 31 \\
\hline 3-й курс & 4 & 21 & $42-57$ & $431,68(142,44)$ & $1,11(0,64)$ & $3,26(1,84)$ & 24 \\
\hline 4-й курс & 9 & 45 & $41-62$ & $348,15(61,41)$ & $1,11(0,32)$ & $2,74(1,59)$ & 28 \\
\hline 5-й курс & 6 & 14 & $42-56$ & $394,63(92,83)$ & $0,9(0,29)$ & $2,71(1,32)$ & 24 \\
\hline
\end{tabular}

При чтении сложных текстов на китайском языке средняя продолжительность фиксаций у носителей языка оказалась аналогичной той же, что и при чтении простых текстов, - 193 мс. У студентов 2-5-х курсов средняя продолжительность фиксаций оказалась несколько выше при чтении сложных текстов, чем при чтении простых текстов, и находилась в пределах от 348 мс для студентов 4-го курса до 432 мс для студентов 3-го курса. Средняя длина прогрессивных саккад у носителей языка осталась на том же уровне, что и при чтении простых текстов (0,9-1,11 знака), однако у сту- дентов 5-го курса средняя длина прогрессивных саккад оказалась незначительно ниже, чем при чтении простых текстов. Средняя длина регрессивных саккад у всех студентов осталась на том же уровне, что и при чтении простых текстов, - от 2,2 знаков до 3,26 знаков. Как и в случае чтения простых текстов, у студентов пятого курса зафиксирована частота регрессий, аналогичная показателям носителей языка.

Результаты чтения простых и сложных текстов на русском языке представлены в табл. 3 и 4 соответственно.

Показатели чтения простых русских текстов

\begin{tabular}{|c|c|c|c|c|c|c|c|}
\hline & КУ & КТ & КБТ & ПФ (мс) & ДПС (знаков) & ДРС (знаков) & ЧР \\
\hline Носители & 31 & 231 & - & $195,59(20,61)$ & $7,26(1,27)$ & $4,92(1,85)$ & 23 \\
\hline Китайцы & 25 & 122 & $36-64$ & $243,49(24,69)$ & $5,61(0,99)$ & $4,11(1,29)$ & 30 \\
\hline
\end{tabular}

Средняя продолжительность фиксаций у китайских студентов (243 мс) оказалась несколько выше значений, зафиксированных у носителей языка (196 Mc). 
Аналогичные результаты обнаруживаются и в показателях саккад: средняя длина прогрессивных $(5,61$ знака) и регрессивных саккад $(4,11$ знака) у китайских участников оказывается несколько ниже аналогичных значений у носителей языка (7,26 и 4,92 знака соответственно). Частота регрессий у китайских респондентов (30 \%) также оказывается несколько выше значений носителей языка (23\%).

Показатели чтения сложных русских текстов

\begin{tabular}{|c|c|c|c|c|c|c|c|}
\hline & КУ & КТ & КБТ & ПФ (мс) & ДПС (знаков) & ДРС (знаков) & ЧР \\
\hline Носители & 31 & 229 & - & $191,4(19,89)$ & $7,53(1,26)$ & $4,65(1,52)$ & 22 \\
\hline Китайцы & 25 & 110 & $36-64$ & $244(22,23)$ & $5,52(0,95)$ & $4,02(1,22)$ & 29 \\
\hline
\end{tabular}

В отличие от ситуации русско-китайского чтения текста сложность текстов не оказала существенного влияния на показатели чтения у билингвов. Так, средняя продолжительность фиксаций при чтении сложных текстов (244 мс) у билингвов осталась на том же уровне, что и при чтении простых текстов (243 мс). Средняя длина прогрессивных (5,52 знака) и регрессивных (4,02 знака) саккад также остались на прежнем уровне (5,61 и 4,11 знака соответственно). Пока- затели частоты регрессий также не претерпели изменений $(29 \%)$ по сравнению с ситуацией чтения простых текстов (30\%).

Дополнительно был проведен статистический анализ зависимости значений показателей чтения от результатов предварительного тестирования с использованием метода смешанных линейных моделей. На рис. 1 и 2 представлены графики эффекта количества баллов за тест на различные показатели чтения.
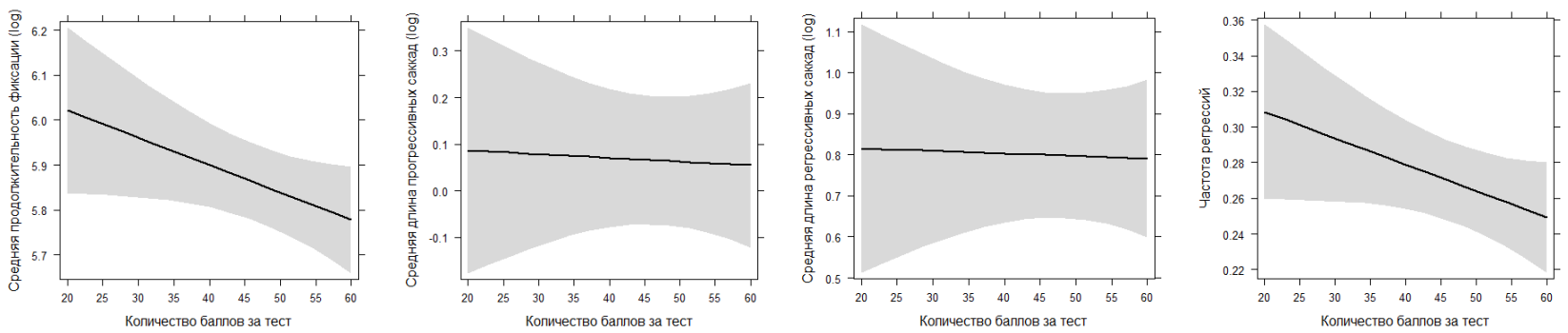

Рис. 1. Графики эффекта количества баллов за тест на различные показатели чтения при билингвальном чтении на китайском языке (слева направо: средняя продолжительность фиксаций, средняя длина прогрессивных саккад, средняя длина регрессивных саккад, частота регрессий)

При чтении текстов на китайском языке для средней продолжительности фиксаций $\left(\chi^{2}=3,923, \mathrm{df}=1\right.$, $p=0,051)$ и частоты регрессий $\left(\chi^{2}=3,206, \mathrm{df}=1\right.$, $p=0,073)$ эффект количества баллов за тест приблизился к статистической значимости. Эффект количе-
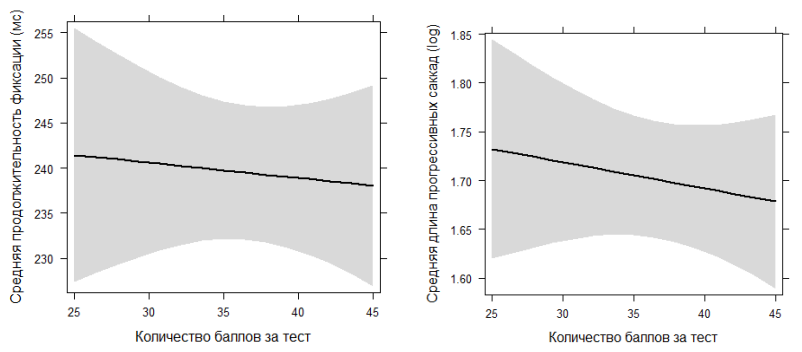

ства баллов за тест на длину прогрессивных $\left(\chi^{2}=0,04\right.$, $\mathrm{df}=1, p=0,85)$ и регрессивных $\left(\chi^{2}=0,016, \mathrm{df}=1\right.$, $p=0,9)$ саккад не оказался статистически значимым. Фактор сложности текстов не оказался значимым ни для одного из показателей чтения.

Рис. 2. Графики эффекта количества баллов за тест на различные показатели чтения при билингвальном чтении на русском языке (слева направо: средняя продолжительность фиксаций, средняя длина прогрессивных саккад, средняя длина регрессивных саккад, частота регрессий)

При чтении на русском языке ни один из эффектов не оказался статистически значимым: средняя продолжительность фиксаций $\left(\chi^{2}=0,11, \mathrm{df}=1, p=0,74\right)$, средняя длина прогрессивных саккад $\left(\chi^{2}=0,43, \mathrm{df}=1\right.$, $p=0,51)$, средняя длина регрессивных саккад $\left(\chi^{2}=0,08\right.$, $\mathrm{df}=1, p=0,78)$, частота регрессий $\left(\chi^{2}=0,31, \mathrm{df}=1, p=\right.$ $0,58)$. Как и при чтении текстов на китайском языке, фактор сложности текстов не оказался значимым ни для одного из показателей чтения.
Обсуждение. Таким образом, в результате проведенного экспериментального исследования, были выявлены следующие особенности процесса чтения китайских текстов русскими студентами.

Самая высокая продолжительность фиксаций оказалась у студентов 1-го курса. Это свидетельствует о том, что студенты 1-го курса испытывают значительные затруднения с обработкой информации, извлекаемой из китайских текстов. Результаты данного экс- 
перимента, однако, не позволяют судить, на каком этапе обработки проявляются наибольшие затруднения. Стоит отметить, что резкое изменение продолжительности фиксаций отмечается только при переходе с перво1-го на 2-й курс. Интересным также представляется тот факт, что ни для одной группы студентов средняя продолжительность фиксаций не оказалась ниже 300 мс - барьера, отмеченного М. Эверсоном в своём исследовании [13. С. 83]. Необходимо также отметить неизменную длину прогрессивных саккад, в три раз уступающую показателям носителей языка. Регрессивные саккады оказались в 2-3 раза длиннее прогрессивных саккад - интересный результат, не наблюдаемый в исследованиях монолингвального чтения. Чем обусловливается необходимость таких длинных регрессивных саккад, остаётся непонятным. Наконец, в показателе частоты регрессий просматривается тенденция к понижению с увеличением языкового опыта студентов. У более низкой частоты регрессий может иметься два объяснения: с одной стороны, снижение частоты регрессий может свидетельствовать о повышении эффективности когнитивной обработки текстового материала билингвом, с другой стороны, это может свидетельствовать о снижении количества ошибочно направленных саккад с увеличением опыта чтения в логографической системе письменности. Второй вариант, однако, представляется маловероятным, учитывая тот факт, что длина в первую очередь прогрессивных саккад у обучающихся остаётся на одном уровне в течение всего периода обучения.

Для китайских студентов, читавших русские тексты, была характерна низкая средняя продолжительность фиксаций, свидетельствующая об отсутствии трудностей с обработкой языковых стимулов на иностранном языке. Средняя длина прогрессивных саккад оказалась несколько ниже, чем у носителей языка, однако не в той степени, которая была зафиксирована у носителей русского языка при чтении на китайском. Регрессивные саккады оказались короче прогрессивных - аналогично результатам носителей языка. Наконец, стоит отметить относительно высокую частоту регрессий у носителей китайского - при чтении на русском они возвращались назад в текст почти так же часто, как начинающие русские студенты при чтении на китайском.

В заключение сопоставим результаты китайскорусского и русско-китайского чтения. В целом китайские участники показали результаты, приближающиеся к результатам носителей русского языка: показатели средней продолжительности фиксаций, средней длины прогрессивных и регрессивных саккад оказались ненамного ниже аналогичных показателей у но- сителей языка. Однако чтений текстов китайской письменности представило значительные затруднения для русских студентов: это выразилось в неизменной длине прогрессивных саккад, высокой средней продолжительности фиксаций даже у студентовстаршекурсников, а также в характере регрессивных саккад, значительно превосходящих прогрессивные саккады по длине.

Представляется, что у засвидетельствованных явлений имеется несколько объяснений. Во-первых, входной уровень русского языка у китайских респондентов оказался значительно выше, чем уровень китайского у русских респондентов. Китайские респонденты изучали русский ещё до приезда в Россию, у многих имеется длительный опыт изучения русского языка - 11 респондентов отметили, что изучали русский в течение 5 лет и более. Таким образом, не представлялось возможным определить показатели чтения для студентов, только начавших изучать русский язык.

Во-вторых, все китайские респонденты указали знание английского - языка, использующего алфавитную систему письменности. Для русских участников знание английского не должно в значительной степени влиять на процесс чтения на китайском языке - оба языка используют алфавитную систему письменности и различаются только орфографиями. Наконец, для обучения детей иероглифической письменности в китайских школах используется фонетический алфавит пиньинь. Всё это приводит к тому, что у взрослых китайцев имеется обширный опыт использования алфавитных систем письменности. Аналогичный опыт отсутствует у носителей русского языка - все иностранные языки, которые они изучали до поступления в университет, используют для письма алфавитные системы письменности.

В перспективах исследования представляется необходимым проследить динамику процесса адаптации к логографической системе письменности у русских студентов, только начинающих изучать китайский язык. Как показало текущее исследование, наибольшие различия в показателях чтения наблюдаются при переходе с первого курса на второй. Лонгитюдное исследование студентов, только начинающих изучать китайский язык, позволило бы проследить динамику изменений с большей точностью. Аналогичное исследование с китайскими участниками представляется мало возможным, в силу того что носители китайского сталкиваются с алфавитными системами письменности уже в раннем возрасте - на том этапе, когда их навык чтения на родном языке является ещё не до конца сформированным.

\section{ЛИТЕРАТУРА}

1. Иванова В.Ф. Современный русский язык: Графика и орфография. М. : Просвещение, 1976.

2. Perfetti C.A. et al. Reading in two writing systems: Accommodation and assimilation of the brain's reading network // Bilingualism: Language and Cognition. 2007. T. 10, № 2. P. 131-146.

3. Chen M.J., Weekes B.S. Effects of semantic radicals on Chinese character categorization and character decision // Chinese Journal of Psychology. 2004. Vol. 46. P. 179-195.

4. Rayner K. Eye movements in reading and information processing: 20 years of research // Psychological bulletin. 1998. Vol. 124 , №. 3. P. $372-422$.

5. Shen E. An analysis of eye movements in the reading of Chinese // Journal of experimental psychology. 1927. № 10 (2). C. 158.

6. Sun F., Feng D. Eye movements in reading Chinese and English text // Reading Chinese script: A cognitive analysis. 1999. P. $189-206$. 
7. Yang H.M., McConkie G.W. Reading Chinese: Some basic eye-movement characteristics // Reading Chinese script: A cognitive analysis. 1999. P. 207-222.

8. Liversedge S.P. et al. Universality in eye movements and reading: A trilingual investigation // Cognition. 2016. Vol. 147. P. 1-20.

9. Shu H. et al. Font size modulates saccade-target selection in Chinese reading // Attention, Perception, \& Psychophysics. 2011. Vol. 73, №. 2. P. 482490.

10. Yan M. et al. Flexible saccade-target selection in Chinese reading // Quarterly Journal of Experimental Psychology. 2010. Vol. 63, №. 4. P. $705-725$.

11. Li X., Liu P., Rayner K. Eye movement guidance in Chinese reading: Is there a preferred viewing location? // Vision Research. 2011. Vol. 51, №. 10. P. 1146-1156.

12. Cop U. et al. Presenting GECO: An eyetracking corpus of monolingual and bilingual sentence reading // Behavior research methods. 2017. Vol. 49, № 2. P. 602-615.

13. Everson M.E. The effect of word-unit spacing upon the reading strategies of native and non-native readers of Chinese: An eye-tracking study : дис. The Ohio State University, 1986.

14. Аверьянова Г.Н. и др. Типовые тесты по русскому языку как иностранному. Второй сертификационный уровень. Общее владение. М. ; СПб. : Златоуст, 1999. $112 \mathrm{c.}$

15. Захарова А.И. Учебно-тренировочные тексты по русскому языку как иностранному. СПб. : Златоуст, 2010.108 с.

16. Андрюшина Н.П. и др. Типовые тесты по русскому языку как иностранному. Первый сертификационный уровень. Общее владение. Второй вариант. М. ; СПб. : Златоуст, ЦМО МГУ. 2011.

17. Hanban/Confucius Institute Headquarters Chinese Proficiency Test Syllabus: Level 4 / Hanban/Confucius Institute Headquarters. Beijing : The Commercial Press, 2009. 75 p.

18. Hanban/Confucius Institute Headquarters Chinese Proficiency Test Syllabus: Level 3 / Hanban/Confucius Institute Headquarters. Beijing : The Commercial Press, 2009.48 p.

19. Council of Europe the Common European Framework of Reference for Languages: Learning, Teaching, Assessment / Council of Europe // Council of Europe. 2001. P. 1-273.

20. Аверьянова Г.Н. и др. Типовые тесты по русскому языку как иностранному. Первый сертификационный уровень. Общее владение. М. ; СПб. : Златоуст, 1999. $112 \mathrm{c.}$

21. Аверьянова Г.Н. [и др.]. Типовые тесты по русскому языку как иностранному. Третий сертификационный уровень. Общее владение. М. ; СПб. : Златоуст, 1999. 112 с.

22. Антонова В.Е. Типовые тесты по русскому языку как иностранному. Базовый уровень. Общее владение. М. ; СПб. : Златоуст, 2007.48 с.

23. Hanban/Confucius Institute Headquarters Chinese Proficiency Test Syllabus: Level 2 // Hanban/Confucius Institute Headquarters. Beijing : The Commercial Press, 2009. 47 p.

24. Hanban/Confucius Institute Headquarters Chinese Proficiency Test Syllabus: Level 5 // Hanban/Confucius Institute Headquarters. Beijing : The Commercial Press, 2009. 75 p.

25. Marian V., Blumenfeld H.K., Kaushanskaya M. The Language Experience and Proficiency Questionnaire (LEAP-Q): Assessing language profiles in bilinguals and multilinguals // Journal of Speech, Language, and Hearing Research. 2007. Vol. 50, № 4. P. $940-967$.

26. Team R.S. et al. RStudio: integrated development for R // RStudio, Inc. Boston, MA. URL: http://www.rstudio.com.

27. Team R.C.R: A language and environment for statistical computing. R Foundation for Statistical Computing. Vienna, Austria, $2016,2017$.

28. Wickham H. Tidyverse: Easily install and load'tidyverse'packages // R package version. 2017. Vol. 1, № 1.

29. Bates D. et al. Package 'lme4'// R foundation for statistical computing. Vienna, 2014. Vol. 12.

30. Машанло Т.Е., Резанова 3.И. Межкультурная письменная коммуникация: чтение текстов алфавитной и логографической систем письменности билингвами // Русин. 2018. № 1 (51). С. 299-311.

Статья представлена научной редакцией «Филология» 30 апреля 2018 г.

THE EFFECT OF L2 PROFICIENCY ON THE EYE MOVEMENT MEASURES DURING L2 READING IN RUSSIANCHINESE AND CHINESE-RUSSIAN LATE BILINGUALS

Vestnik Tomskogo gosudarstvennogo universiteta - Tomsk State University Journal, 2018, 433, $22-30$.

DOI: $10.17223 / 15617793 / 433 / 3$

Timur E. Mashanlo, Tomsk State University (Tomsk, Russian Federation). E-mail: mashanlote@gmail.com

Keywords: eye movements; bilingualism; Chinese; Russian; reading.

In order to investigate how L2 learners adapt to reading in a different writing system the author set up an eye-tracking experiment in which participants with varying degrees of proficiency read texts in L2. 31 Russian-Chinese late bilinguals, 28 Chinese-Russian late bilinguals, all students of Tomsk State University, participated in the experiment. Prior to conducting the experiment, participants were administered proficiency assessment tests comprised of four reading tasks taken from standardised HSK and TORFL proficiency tests. During the experiment, participants read 25 texts in both Chinese and Russian while their eye movements were recorded using an SMI Red 500 eye-tracking system with a sampling rate of $500 \mathrm{~Hz}$. The resulting data were analysed using linear mixed models realised in $\mathrm{R}$ language through lme4 package. Proficiency was entered as a fixed factor, participant and stimulus indices were entered as random factors. Russian first year students had longer fixations ( $480 \mathrm{~ms})$ than their more experienced counterparts (330-400 ms) when reading Chinese; students also made fewer regressions as their proficiency in L2 increased (32\% and $24 \%$ for the first- and the fifth-year students respectively). Both of those measures approached significance: average fixation duration $\left(\chi^{2}=3.82, \mathrm{df}=1, \mathrm{p}=0.051\right)$, regression rate $\left(\chi^{2}=3.21, \mathrm{df}=1, \mathrm{p}=0.073\right)$. Saccade length measures remained consistent across participants of all proficiency levels: $0.9-1.2$ character spaces for progressive, 2.2-3.2 character spaces for regressive saccades. Interestingly, regressive saccades were two to three times longer than progressive saccades for all Russian participants. Chinese students showed no signs of change in their eye movements measures associated with an increase in L2 proficiency: fixation durations $(240 \mathrm{~ms})$, regression rate $(30 \%)$, progressive saccade length (5.6 characters), regressive saccade length ( 4.1 characters). The lack of change in the eye movements of the Chinese students can be attributed to their life-long exposure to alphabetic writing systems through the English language and the Chinese phonetic alphabet (Pinyin). Russian students, on the other hand, have no prior exposure to logographic writing systems, and thus need time to adapt to a writing system that is based on a different sound mapping principle.

\section{REFERENCES}

1. Ivanova, V.F. (1976) Sovremennyy russkiy yazyk: Grafika i orfografiya [Modern Russian language: Graphics and spelling]. Moscow: Prosveshchenie. 
2. Perfetti, C.A. et al. (2007) Reading in two writing systems: Accommodation and assimilation of the brain's reading network. Bilingualism: Language and Cognition. 10(2). pp. 131-146. DOI: 10.1017/S1366728907002891

3. Chen, M.J. \& Weekes, B.S. (2004) Effects of semantic radicals on Chinese character categorization and character decision. Chinese Journal of Psychology. 46. pp. 179-195.

4. Rayner, K. (1998) Eye movements in reading and information processing: 20 years of research. Psychological Bulletin. 124(3). pp. 372-422.

5. Shen, E. (1927) An analysis of eye movements in the reading of Chinese. Journal of Experimental Psychology. 10 (2). pp. 158-183. DOI: $10.1037 / \mathrm{h} 0075609$

6. Sun, F. \& Feng, D. (1999) Eye movements in reading Chinese and English text. In: Wang, J. et al. (eds) Reading Chinese script: A cognitive analysis. N.Y.: Psychology Press.

7. Yang, H.M. \& McConkie, G.W. (1999) Reading Chinese: Some basic eye-movement characteristics. In: Wang, J. et al. (eds) Reading Chinese script: A cognitive analysis. N.Y.: Psychology Press.

8. Liversedge, S.P. et al. (2016) Universality in eye movements and reading: A trilingual investigation. Cognition. 147. pp. 1-20. 10.1016/j.cognition.2015.10.013

9. Shu, H. et al. (2011) Font size modulates saccade-target selection in Chinese reading. Attention, Perception, \& Psychophysics. 73(2). pp. 482-490.

10. Yan, M. et al. (2010) Flexible saccade-target selection in Chinese reading. Quarterly Journal of Experimental Psychology. 63(4). pp. 705-725. DOI: $10.1080 / 17470210903114858$

11. Li, X., Liu, P. \& Rayner, K. (2011) Eye movement guidance in Chinese reading: Is there a preferred viewing location? Vision Research. 51(10). pp. 1146-1156. DOI: 10.1016/j.visres.2011.03.004

12. Cop, U. et al. (2017) Presenting GECO: An eyetracking corpus of monolingual and bilingual sentence reading. Behavior Research Methods. 49(2). pp. 602-615. DOI: 10.3758/s13428-016-0734-0

13. Everson, M.E. (1986) The effect of word-unit spacing upon the reading strategies of native and non-native readers of Chinese: An eye-tracking study: dis. The Ohio State University.

14. Aver'yanova, G.N. et al. (1999) Tipovye testy po russkomu yazyku kak inostrannomu. Vtoroy sertifikatsionnyy uroven'. Obshchee vladenie [Typical tests in Russian as a foreign language. The second certification level. General knowledge]. Moscow; St. Petersburg: Zlatoust.

15. Zakharova, A.I. (2010) Uchebno-trenirovochnye teksty po russkomu yazyku kak inostrannomu [Teaching and training texts on Russian as a foreign language]. St. Petersburg: Zlatoust.

16. Andryushina, N.P. et al. (2011) Tipovye testy po russkomu yazyku kak inostrannomu. Pervyy sertifikatsionnyy uroven'. Obshchee vladenie. Vtoroy variant [Typical tests in Russian as a foreign language. The first certification level. General knowledge. The second variant]. Moscow; St. Petersburg: Zlatoust, TsMO MGU.

17. Hanban/Confucius Institute Headquarters. (2009) Chinese Proficiency Test Syllabus: Level 4. Beijing: The Commercial Press.

18. Hanban/Confucius Institute Headquarters. (2009) Chinese Proficiency Test Syllabus: Level 3. Beijing: The Commercial Press.

19. Council of Europe. (2001) The Common European Framework of Reference for Languages : Learning, Teaching, Assessment. Council of Europe. pp. 1-273.

20. Aver'yanova, G.N. et al. (1999) Tipovye testy po russkomu yazyku kak inostrannomu. Pervyy sertifikatsionnyy uroven'. Obshchee vladenie [Typical tests in Russian as a foreign language. The first certification level. General knowledge]. Moscow; St. Petersburg: Zlatoust.

21. Aver'yanova, G.N. et al. (1999) Tipovye testy po russkomu yazyku kak inostrannomu. Tretiy sertifikatsionnyy uroven'. Obshchee vladenie [Typical tests in Russian as a foreign language. The third certification level. General knowledge]. Moscow; St. Petersburg: Zlatoust.

22. Antonova, V.E. (2007) Tipovye testy po russkomu yazyku kak inostrannomu. Bazovyy uroven'. Obshchee vladenie [Typical tests in Russian as a foreign language. A basic level. General knowledge]. Moscow; St. Petersburg: Zlatoust.

23. Hanban/Confucius Institute Headquarters. (2009) Chinese Proficiency Test Syllabus: Level 2. Beijing: The Commercial Press.

24. Hanban/Confucius Institute Headquarters. (2009) Chinese Proficiency Test Syllabus: Level 5. Beijing: The Commercial Press.

25. Marian, V., Blumenfeld, H.K. \& Kaushanskaya, M. (2007) The Language Experience and Proficiency Questionnaire (LEAP-Q): Assessing language profiles in bilinguals and multilinguals. Journal of Speech, Language, and Hearing Research. 50(4). pp. 940-967.

26. RStudio: integrated development for R. RStudio, Inc., Boston, MA. [Online] Available from: http://www.rstudio.com.

27. R Core Team. (2016) $R$ : A language and environment for statistical computing. Vienna, Austria: R Foundation for Statistical Computing.

28. Wickham, H. (2017) Tidyverse: Easily install and load 'tidyverse' packages. $R$ package version. 1(1).

29. Bates, D. et al. (2014) Package 'Ime4'. R Foundation for Statistical Computing. 12.

30. Mashanlo, T.E. \& Rezanova, Z.I. (2018) Intercultural written communication: bilingual reading of texts written in alphabetic and logographic writing systems. Rusin. 1 (51). pp. 299-311. (In Russian). DOI: 10.17223/18572685/51/19 